\title{
LCA in Japan: State of the Art
}

\section{Life Cycle Assessment: From Adam Smith to Aristotle}

\author{
A Review of the Third International Conference on Ecobalances \\ Tsukuba, Japan, November 25-27, 1998 \\ David Hunkeler ${ }^{1}$, Ryoichi Yamamoto ${ }^{2}$, Itaru Yasui ${ }^{3}$ \\ ' Department of Chemistry, Swiss Federal Institute of Technology, $\mathrm{CH}-1015$ Lausanne, Switzerland \\ ${ }^{2}$ Institute of Industrial Science, University of Tokyo, Tokyo 106, Japan \\ ${ }^{3}$ Center for Collaborative Research, University of Tokyo, Tokyo 106, Japan
}

\section{Overview}

The Third International Conference on EcoBalances was held in Tsukuba, Japan, November 25th-27th, 1998 attracting 460 participants. The conference has grown from the prior meetings in 1994 and 1996 which introduced life cycle assessment into Japanese academia and industry. The 159 papers presented from authors representing each major developed and developing regions of the globe, make the EcoBalance III Conference the largest LCA-related meeting in the world. The Third Conference focused on the application of life cycle assessment, as well as its associated fields of life cycle management, ecodesign and life cycle thinking, towards both practical industrial cases as well as national and supranational policy related issues. The sub-theme of the conference was movement towards sustainability and, as will be discussed, significant progress has been made to evolve the life cycle concept into a practical tool. Indeed, a primary conclusion of the conference was that a move towards industrial ecology would require a shift in the development of firm based assessment methods (Design for Environment, Ecomaterial Selection, Life Cycle Assessment) to those which could be oriented towards multistakeholders, specifically consumers, and related in terms of market parameters such as value. The rigorous methods, via the development of ecometrics, were seen as means for validating such tools.

The Conference opened with a plenary lecture by TAKAMITSU SAWA of Kyoto University discussing the economic implications of last year's Kyoto summit. Specifically, the targets for $\mathrm{CO}_{2}$ reductions by 2012 are foreseen to result in a global market for "tradable permits". North America, the EU, Oceanasia (Australia and New Zealand) as well as Japan, who all negotiated different $\mathrm{CO}_{2}$ quotas, are expected to be buyers whereas countries presently suffering recessions, such as those in the former Soviet Union, are likely to be sellers. The effect of government policy, such as Sweden's decision to decommission nuclear reactors by 2010 , will contribute to the global $\mathrm{CO}_{2}$ concentrations and the permit price. The Kyoto agreement was compared to the Montreal Protocol banning CFC production. Mario Molina, the Nobel prize chemist, has recently shown that the concentration of methyl chloride in the atmosphere is lower then in 1987 , citing this as the first positive evidence that mankind can positively effect the environment.
This observation set the theme for a large part of the conference as the microeconomic, and local environmental, effects of production can now be linked to global phenomena such as atmospheric concentrations, soil and sea water levels, and average annual temperature.

A panel discussion, where seven panelists presented their views on the current state of Ecobalances, can be summarized by Figure 1. Mark Goedkoor (Pré Consultants) noted that we have useful tools, such as LCA, to evaluate the "technosphere"; however, the "ecosphere" and "valuesphere" require adequate metrics. He also noted that the evaluation of sustainability requires a relative valuation between present and future generations with egalitarians preferring a balance whereas individualists and hierarchists are skewed to the short and long term respectively. Friedrich SCHMIDT-BlEEK noted that while LCA must be scientific in nature, the problems that it is used to assess are not. Furthermore, unless macroeconomic indicators of wealth, such as GDP, are displaced, LCA will have to be converted into a unit resembling a price, so that the existing markets can accommodate it. He recommends examining the input side of the economy, specifically resource productivity, and his "Factor 10" approach indicates that the utility of resources will have to improve by an order of magnitude if the current population in the developed, and developing, worlds are to have access to a similar environmental and economic quality of life. The need for LCA communication was highlighted by both JEROEN ROMBOUTS (Delft University) and SUKEHIRO GOTOH (National Institute of the Environment, Japan).

ITARU YASUI (University of Tokyo) mentioned that there are three types of environmental burdens based on: 1) pollution (e.g. NOx, SOx, COD), 2) Consumption (e.g. energy, resources, solid waste) and 3) Background. The later includes non-regulated pollutions such as drinking water in the sewage system. While significant inroads have been made to decrease, in absolute terms, the amount of production-based emissions, the consumption-based releases now dominate with background also rising. Therefore, reductions in emissions, in both absolute and relative terms, are required. However, the scaling factor for the denominator of such a ratio, traditionally GDP, requires reconsideration with utility per unit service suggested by the panel as a whole. In general, all panelists concurred that LCA required a preliminary impact assessment prior to the inventory stage in order to 


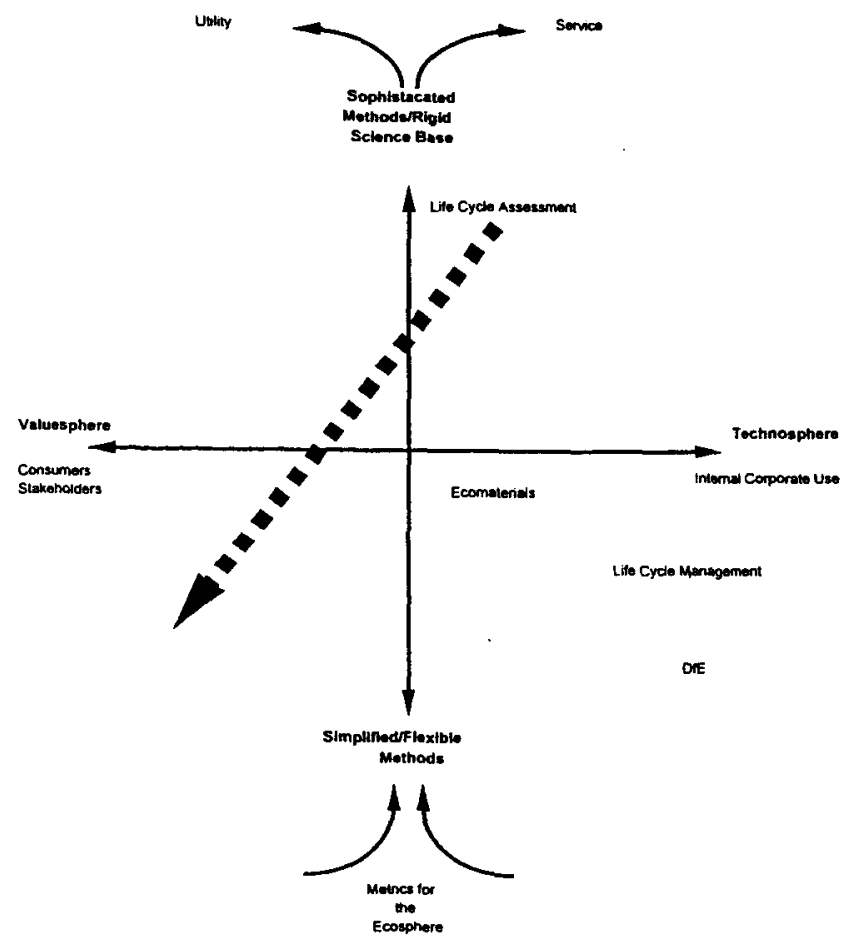

Fig. 1: Categorization of ecobalance related methods which have been developed according to their degree of complexity and intended application. The technosphere designates an industrial or firm based approach whereas the valuesphere significs a consumer/product based scheme. The majority of present activities are simplified methods aimed for internal corporate use (e.g. DfE) or relatively detailed procedures such as life cycle assessment. A predicted shift from sophisticated methods which do not scrve either corporate or consumer needs to more simplified methods, understandable by multi-stakeholders, aimed at the product is shown by the dashed line.

reduce the time, and cost, of the analyses, and to focus the problem into a critical analysis where only the most relevant data are collected, in analogy to the microeconomic evaluation of under performing firms. Yasur's method is based on the consumption of time until an environmental crises whereas other methods are based on willingness to pay (EPS, Sweden), the environmental capacity of a nation (Ecopoints, Switzerland), and the effect on a local, in this case the EU, ecosystem (Ecoindicator'95, NL). The impact factor, according to YASUI, is the ratio of the fatality, defined as the percentage of the population affected, and the consumption of time, in years.

The conference included seventeen oral sessions with simultaneous translations between English and Japanese and vice versa. Specific topics included Impact Assessment ( 9 papers), Methodology (6 papers), Ecodesign (4 papers) as well as Social Infrastructure/Ecosystem ( 7 papers) and Strategic Decision Making (8 papers). Case study related sessions were dedicated to Automobiles, Household/Electric Products, Transport Equipment, Foods/Agriculture, Municipal Waste Management and the Construction sector. Break-out areas focusing on Ecomaterials, Recycling and an update on progress in Asian countries were also included. One poster session focused on case studies as well as demonstrations of novel advances in life cycle related software including Ashby's Ecomaterial Selector (University of Cambridge) which is currently a teaching tool in over 300 universities. Updates to established databases, such as the Boustead model, were also presented. This brief review will not highlight the near 200 contributions which are excellently summarized in the conference publication available in English and Japanese [1]. Rather, we will summarize the issues related to recommendations for future activities in the life cycle and industrial ecology areas.

\section{Issues}

\subsection{Materials selection}

Norihiro ITsubo (Japan Environmental Management Association for Industry) has established a single environmental index which is a function of resource consumption and availability, human health and ecosystem well-being. It is based on established impact categories including resource depletion, human toxicity, ozone depletion and greenhouse gas emissions, categorized into the aforementioned resource, human health and ecosystem subdomains. With value systems, or weightings, of the three subdomains varying from uniform to 2:3:3, an impact assessment methodology which is an alternative to Eco-Indicator'95, EPS, the material intensity per service unit (MIPS) and the EcoPoint have been developed. In general, the JEMAI method places a slightly greater weighting on plastics such as polypropylene and polyethylene relative to metals such as secondary aluminum and glasses. Clearly, there is no attempt to define a single impact assessment methodology for all cases, however, certain weightings are more appropriate for local decision making given the difference in the energy mix and disposal options available in various countries. In a similar paper, DOUN WENG (Tsinghua University, China) has defined a dimensionless ecoindicator as the ratio of an environmental variable and a measure of service performance such as tensile strength, heat capacity or conductivity. Clearly; the JEMAI method is suitable for macroor policy-related decisions whereas the later can be more usefully applied to ecodesign.

Keisuke Matsuhashl (National Institute for Environmental Studies, Japan) presenred the conclusions of a survey where environmental problems areas and safeguard subjects (human health, ecosystem, resources, welfare) were prioritized in Japan. The multi-stakeholder panel based approach provides a means of prioritizing environmental issues and can serve as an alternative weighting system for impact assessments. JEROEN GUINÉE (Leiden University) concurred noting that the identification of the key issues, via the selection of the most appropriate impact categories, is essential if LCA is to become a widespread tool. JEROEN ROMBOUTS, in discussing corporate perspectives, noted that life cycle prioritization is important in both communication to stakeholders as well as influencing the issues that a firm can best manipulate. Standardization of LCA, while important for multinational policy-related issues is not likely to be required industrially with a type of environmental accounting preferred. Additionally, if one utilizes the life cycle concept in the design of specific products, then it is clear that significant environmental improvements can be made via the issuing of list of banned/ preferable as well as recyclable or compatible materials to de- 
signers (PHILlupe Osset, Ecobilan, France). Evidently, these lists require justification with a systematic approach such as life cycle assessment, however, once such analyses have been performed for given industries, the results (lists) are often more useful than the cases since some designers require tools they can use rapidly. An example of the larer is an integrated circuit designer, who, given the short design cycle, requires a tool which can be applied, in full, in a matter of hours.

\subsection{Methodology}

Bo WeIdemA (Technical University of Denmark) presented an elegant characterization of life cycle assessment according to the time scale under consideration and the degree of specificity of the analyses. He noted that long term studies tend to be generic in nature and apply a rather full LCA methodology. In contrast, EcoBalance III has shown that many specific case studies have been performed, under industrially relevant conditions, in a streamlined life cycle management framework.

KoHmei HaLADA (National Research Institute for Metals, Japan) illustrated excellent correlations between the logarithms of the half-lives of $\mathrm{CO}_{2}$ emissions with energy and $\mathrm{BOD}$ respectively, providing some justification for the use of $\mathrm{CO}_{2}$ as a single normalized environmental metric, as is the common practice.

\subsection{Economic and technical associations}

MARK GoEDKoor has developed an "E2 vector" which compares the environmental load to the economic value added for each stage in the life cycle. An evaluation of the cumulative environmental load, relative to the life cycle value added, provides a useful indicator for decision making. While some "win-win" situations can easily be identified, for example car sharing which is becoming popular in the EU, other E2 analyses show that consumers will pay an economic premium for enhanced utility based in part on the environment. For example, in The Netherlands consumers purchase vegetables by "subscription" receiving a different allotment of legumes each week as the season, and life cycle burden, permit. While the economic cost is slightly higher, the environmental load is so significantly reduced, primarily due to drastically reduced transportation costs, that the program has increased in popularity.

KonRad SAUR (Product Engineering, Dettingen, Germany) has developed a three-dimensional plot which illustrates the technical efficiency, environmental load and life cycle cost of various alternatives. The visual aid provides a facile means of product comparison and has been extensively applied in the automotive industry.

FRIEDRICH SCHMIDT-BLEEK noted that a key indicator of sustainability is the service unit per resource input (i.e. the reciprocal of MIPS). When questioned as to what extent one could expect to change resource supply, so key an element in the global GDP, without leading to a heightened amplitude in the macroeconomic cycle, and hence deeper periodic recessions, SCHMIDT-BLEEK replied that fiscal reform, for example the substitution of income- with carbon-based taxes, would likely require the redefinition of wealth away from purely economic terms. On a micro- economic level, some industries clearly sell you services in units which are translated into personal utility and total costs, such as airline travel. However, resource-consuming products with long economic life cycles, including the automobile, require redefinition of their utility or functionality. Therefore, the car itself cannot serve as the functional unit for an analyses since it is the transportation service as a whole, and its integration with other sectors, which will, in the end, have to be sustainable.

\subsection{Needs and future trends}

At the conclusion of the conference, the panelists were reassembled to respond to questions posed by the participants. Key issues for the immediate future were increasing the awareness of life cycle concepts, thereby calling for clear communication between the experts, and industry, and the audience/consumer. Common and open databases are also under construction with Japan taking the lead in this area. Further research on LCA methodology was deemed not to be needed, per se, with the exception of the development of sophisticated policy related tools which can related to macroecometrics such as global temperatures and concentrations. However, the need to integrate product based methods such as LCM with organizational issues (e.g. EMS) will have to be addressed if life-cycle based methods are to be as practical as presently foreseen. Furthermore, the establishment, and linking, of environmental indicators with costs is seen to be key.

The conference concluded by noting that all the conditions do not have to be satisfied to justify a beginning and Ecobalances must be developed for large scale evaluations while, in parallel, adapted to industrially relevant product, and more appropriately service, based cases. If Adam Smith can be viewed as a prophet in his treatise on the Wealth of Nations, then perhaps the environmental issue will best define the 21 st century, more so then other socio-political movements which have dominated the past eighty years. If we are to redefine wealth away from the national-product paradigm, then perhaps Aristotle can himself be renewed in this respect for it is he who noted that "true human wealth lies in the use of products not their ownership". Are we then not speaking of the Wealth of People as measured by the utility of the services they have access to?

The next meeting on EcoBalances, "EcoBalance 21 ", is scheduled for September 2000 in Tsukuba, and is, at this point, intended to be a multi-stakeholder conference involving sociologists, economists, political scientists and religious representatives in additional to the traditional governmental, academic and industrial participants. The key focus will be implementation of practical, and validated, methodologies which can unambiguously, though qualitatively, lead toward sustainability.

\section{Literature cited:}

[1] Proceedings of the Third International Conference on EcoBalance, Tsukuba, Japan, November 25-27, 1998 (Available from The Society of Non-Traditional Technology, Kotohira Kaikan Bldg. 3F, 1-2-8, Tranomon, Minato-ku, Tokyo 1005-0001, JAPAN) 